\title{
SOCIODEMOGRAPHIC, LIFESTYLE AND HEALTH FACTORS ASSOCIATED WITH DEPRESSION AMONG ADULTS IN MALAYSIA: AN ETHNIC COMPARISON
}

\author{
Cheah $\mathrm{YK}^{1,2}$, Azahadi $\mathrm{M}^{3}$, Phang $\mathrm{SN}^{4}$ and Abd Manaf $\mathrm{NH}^{5}$. \\ ${ }^{1}$ School of Economics, Finance and Banking, College of Business, Universiti Utara Malaysia, 06010 UUM Sintok, Kedah \\ Darul Aman, Malaysia \\ ${ }^{2}$ The Center for Health and the Social Sciences (CHeSS), University of Chicago, 5841 S. Maryland Ave, Chicago, IL 60637 \\ ${ }^{3}$ Centre for Burden of Disease Research, Institute for Public Health, Ministry of Health Malaysia, Jalan Setia Murni U13/52, \\ Alam Nusantara, 40170 Shah Alam, Selangor, Malaysia. \\ ${ }^{4}$ School of Government, College of Law, Government and International Studies, Universiti Utara Malaysia, 06010 UUM \\ Sintok, Kedah Darul Aman, Malaysia \\ ${ }^{5}$ Department of Business Administration, Faculty of Economics and Management Sciences, International Islamic University \\ Malaysia, 50728 Kuala Lumpur, Malaysia
}

\author{
Correspondence: \\ Yong Kang Cheah \\ School of Economics, Finance and Banking, \\ College of Business, \\ Universiti Utara Malaysia, \\ 06010 UUM Sintok, \\ Kedah Darul Aman, Malaysia. \\ Email: cheahykang@gmail.com
}

\begin{abstract}
Background: Depression is a serious mental health illness worldwide. The purpose of the study was to investigate the relationships between depression and its risk factors of sociodemography, lifestyle, and health among the adults of the different ethnic groups in Malaysia.

Method: A nationwide database with 10141 observations was used. Multivariable logistic regression analyses stratified by ethnicity were estimated.

Results: Ethnicity and gender, age, education, marital status and self-rated health were correlated to the likelihood of having depression. Malay females and smokers (AOR: 2.083) were more likely to suffer from depression than Malay males (AOR: 0.305) and non-smokers. Higher-income Chinese displayed higher odds of having depression than lower-income Chinese (AOR: 1.009). Indians and others with secondary-level education displayed a lower likelihood of developing depression compared to those with primary-level education (AOR: 0.587).

Conclusion: This study could contribute significantly to the formulation and development of an effective policy directed towards reducing the prevalence of depression in the vulnerable. These were the adults, in the younger age group, with lower education, with self-rated poor health, being female, unmarried, Malay and Chinese, and Indians and others. A nationwide policy targeted towards the Malay females to reduce their depression, with attention to the Chinese with a high income, and to the Indians and others with poor educational background to improve their knowledge of mental health, would be worthy of consideration.
\end{abstract}

Keywords: depression, ethnicity, gender, lifestyle, mental health

\section{Introduction}

Depression is no longer uncommon as approximately 300 million people globally suffer from the mental disorder (1). It poses a serious challenge to daily life, leading to a multitude of problems: weight gain, insomnia, and chronic fatigue; disturbance in mood and loss of concentration; and poor performance at work and school with problems in the family $(2,3)$. There was also evidence suggesting that depression is highly associated with suicide, a significant cause of mortality among adults $(4,5)$. 
Depression is preventable. Preventive approaches have often been adopted, with cognitive and social skills in schools, and physical activity programmes for the elderly in the community (6). There is also medical care with antidepressant drugs and psychotherapy. However, this is underutilised, especially by those in developing countries from lack of resources, poor mental health awareness, social stigma and an unwillingness to report symptoms $(7,8)$.

In Malaysia, it was claimed in a news report that approximately $40 \%$ of adults would suffer from mental health problems including depression in their lifetime (9). The popular national report quoted a prevalence rate of depression was only $1.8 \%$, which was likely an error in reporting (9). Mukhtar and Oei found that $6-18 \%$ of Malaysians had depression (10). ZamZam et al. employed a self-assessed screening measure and found that $14.4 \%$ of adult patients in a primary healthcare centre suffered from depression (11). Using a patient health questionnaire (PHQ-9), Tan and Yadav found that $12.3 \%$ of low-income urban adults had depression. These facts and figures were alarming and would raise the concern of public health administrators (12).

An understanding of the types of individuals likely or unlikely to suffer from depression was essential for policy development in Malaysia. The main factors found to correlate with depression in the studies in Malaysia were sociodemography of income, age, family size, gender, ethnicity, marital status and employment status; lifestyle with physical activity and smoking; and health with selfrated health and chronic illnesses $(8,13-18)$. However, studies on the ethnic variation of these factors were missing. The data in those studies were limited as they were collected in the states or regions and were not truly descriptive of the Malaysian population. The present study was conducted in the light of these research gaps.

The primary main objective of this study was to examine the factors associated with depression among adults in Malaysia with an investigation of the sociodemographic, lifestyle and health differences in depression across ethnic groups, differing from previous studies which took account of ethnic variables but failed to stratify their analyses by ethnicity. The data derived from a nationwide sample with a large set of observations could enable a comparison of the factors related to depression with past regional studies.

\section{Materials and methods}

\section{Data Collection}

The National Health and Morbidity Survey 2011 (NHMS 2011) was a nationwide survey conducted by the Ministry of Health Malaysia, from 17 April 2011 to 27 July 2011, with a questionnaire, developed and validated, to determine the pattern of health problems among Malaysians (19) and released for public access in 2014. The country was divided into 794 geographically contiguous areas termed Enumeration Blocks (EB) for a first stage sampling. Each EB was subdivided into smaller units termed Living Quarters (LQ). Twelve LQs were randomly selected from each EB, and the members of their households were surveyed in a second stage sampling. The inclusion criteria were individuals aged 18 years or above regardless of gender and ethnic background. Exclusion criteria were institutionalised individuals. The selected respondents were not allowed to participate in the survey if their written consents were not obtained. Trained interviewers offered the questionnaires in face-to-face interviews in English, Malay, Chinese and Tamil. The total sample size in the analysis was 10141 respondents, and the response rate was 93\%. The targeted sample size was calculated based on three criteria: expected prevalence of illnesses in the population; a marginal error of 0.01-0.05; and a confidence level of $95 \%$. The survey was approved by the Medical Research and Ethics Committee, Ministry of Health Malaysia.

With approval for access and usage of NHMS 2011 for our research from the Director General of the Ministry of Health, the raw data was processed by the Institute for Public Health (IPH) according to our objectives of the research. We further processed the data by deleting the observations with incomplete information or missing data before our analyses as removal of randomly missing data would not cause biased results.

\section{Variables}

The explained variable used in this study, depression, was based on self-reports from the participants. The respondents were asked if they were ever depressed or down, for most of the time, nearly every day, or for two weeks. The respondents who answered in the affirmative were considered to have depression. Although self-report of depression could be associated with a reporting error, its validity was adequate and appropriate in research (20).

The explanatory variables used in this study could be grouped into three categories: sociodemography of income, age, household size, gender, ethnicity, education, marital status and employment status; lifestyle with physical activity and smoking; and health factors with selfrated health. These risk factors were selected based on previous studies relating to depression $(8,13-18)$.

Age, income and household size were used as continuous variables with the individual monthly income in Ringgit Malaysia (RM) and the number of members in each household for household size. The date of birth of the respondent was used to calculate age in years. Age was formatted as a continuous variable. Ethnic variables comprised of three categories: Malay, Chinese and Indian/ others. As only a small proportion of the respondents were from other ethnic groups, they were grouped with the Indian as Indian/others. The highest education level of the respondents was collapsed to form three categories: tertiary, secondary and primary. It was expected that unmarried individuals might display different stress levels from married individuals given the lack of spousal support. Hence, the marital status was categorised into two groups 
to facilitate comparison: married and unmarried who were single or divorced or widowed. The employment status was also grouped into two groups: the employed and the unemployed.

In terms of physical activity, two questions were asked: the performance of a vigorous or moderate physical activity in the preceding seven days, and the number of days and the length of time devoted to the vigorous or moderate physical activity. The answers were then used to calculate the Metabolic Equivalents (METs) in minutes per week $(19,21)$. The respondents reported their smoking status when asked if they were smokers. They were categorised as smokers if the answer was in the affirmative. The respondents were asked to rate their health as very good, good, fair, not good or very bad. The answers were then categorised into three groups: good which was very good or good; fair; and poor which was not good or very bad.

\section{Statistical analysis}

Descriptive statistics of all the explanatory variables were calculated. For income, age and household size variables, mean and standard deviation were estimated according to Cheah and Goh (22) and Cheah and Rasiah (23) where distributions of continuous variables were described using mean. For others, percentage and frequencies were calculated. Our study used multivariable logistic regression to examine the independent relationships between depression and sociodemographic, lifestyle, and health factors. Regressions stratified by ethnicity were estimated for the Malay, the Chinese and the Indian/others. The likelihood ratio (LR) statistics were obtained to identify the overall significance of the regressions. The significance level was set at $p<0.05$.

\section{Results}

Characteristics of survey respondents were illustrated in Table 1. The average monthly individual income was RM 1653.33. The average age and family sizes were approximately 41 years and four members, respectively. Slightly more than half of the respondents were females (53.89\%). The ethnic breakdown consisted of $51.78 \%$ Malays, $25.43 \%$ Chinese and $22.79 \%$ Indians/others. The majority of the respondents had a secondary-level education (47.52\%), while only $26.39 \%$ and $26.09 \%$ had a tertiary-level and a primary-level education, respectively. The majority were married (68.21\%) and employed (64.66\%). Of the total respondents, $61.37 \%$ were physically active, and $21.20 \%$ were smokers. In terms of self-rated health, $79.99 \%, 18.17 \%$ and $1.84 \%$ rated their health as good, fair and poor, respectively.

Table 2 illustrated the adjusted odds ratio of having depression. The LR statistics was highly significant, and this indicated that all the explanatory variables were jointly significant in explaining depression. In addition, a very high proportion of the outcomes were correctly explained by the regression (97.60\%). Moreover, omitted variable bias might not be an issue as the constant term was insignificant. It
Table 1: Characteristics of survey respondents

\begin{tabular}{|c|c|c|}
\hline Variables & $\begin{array}{c}\text { Mean / } \\
\text { Percentage }\end{array}$ & $\begin{array}{l}\text { Std. Dev. / } \\
\text { Frequency }\end{array}$ \\
\hline Income & 1653.33 & 2235.36 \\
\hline Age & 41.18 & 15.41 \\
\hline Family size & 4.41 & 2.24 \\
\hline \multicolumn{3}{|l|}{ Gender } \\
\hline Male & 46.11 & 4676 \\
\hline Female & 53.89 & 5465 \\
\hline \multicolumn{3}{|l|}{ Ethnicity } \\
\hline Malay & 51.78 & 5251 \\
\hline Chinese & 25.43 & 2579 \\
\hline Indian/others & 22.79 & 2311 \\
\hline \multicolumn{3}{|l|}{ Education } \\
\hline Tertiary & 26.39 & 2676 \\
\hline Secondary & 47.52 & 4819 \\
\hline Primary & 26.09 & 2646 \\
\hline \multicolumn{3}{|l|}{ Marital status } \\
\hline Married & 68.21 & 6917 \\
\hline Unmarried & 31.79 & 3224 \\
\hline \multicolumn{3}{|l|}{ Employment } \\
\hline Employed & 64.66 & 6557 \\
\hline Unemployed & 35.34 & 3584 \\
\hline \multicolumn{3}{|c|}{ Physical activity } \\
\hline Active & 61.37 & 6224 \\
\hline Inactive & 38.63 & 3917 \\
\hline \multicolumn{3}{|l|}{ Smoking } \\
\hline Smoker & 21.20 & 2150 \\
\hline Non-smoker & 78.80 & 7991 \\
\hline \multicolumn{3}{|c|}{ Self-rated health } \\
\hline Good & 79.99 & 8112 \\
\hline Fair & 18.17 & 1843 \\
\hline Poor & 1.84 & 186 \\
\hline Observations & \multicolumn{2}{|c|}{10141} \\
\hline
\end{tabular}

Note: Std. Dev. refers to standard deviation. For income, age and family size variables, the values refer to mean and standard deviation. For others, the values refer to percentage and frequency.

Source: NHMS 2011

could, therefore, be concluded that the model was well specified. Age was correlated to a decreased likelihood of developing depression [adjusted odds ratio (AOR): 0.985]. Gender was a significant independent factor associated with depression, as males are were less likely to develop 
Table 2: Factors associated with depression: Pooled sample

\begin{tabular}{|c|c|c|}
\hline Variables & AOR & $95 \% \mathrm{Cl}$ \\
\hline Constant & 1.001 & $0.447,2.245$ \\
\hline Income $/ 100^{\#}$ & 1.002 & $0.996,1.009$ \\
\hline Age & $0.985^{*}$ & $0.974,0.995$ \\
\hline Family size & 0.988 & $0.934,1.045$ \\
\hline \multicolumn{3}{|l|}{ Gender } \\
\hline Male & $0.561 *$ & $0.396,0.796$ \\
\hline Female $^{a}$ & 1.000 & - \\
\hline \multicolumn{3}{|l|}{ Ethnicity } \\
\hline Malay & $0.615^{*}$ & $0.457,0.828$ \\
\hline Chinese & $0.355^{*}$ & $0.231,0.543$ \\
\hline Indian/others ${ }^{a}$ & 1.000 & - \\
\hline \multicolumn{3}{|l|}{ Education } \\
\hline Tertiary & $0.627^{*}$ & $0.407,0.967$ \\
\hline Secondary & $0.659 *$ & $0.466,0.932$ \\
\hline Primary ${ }^{a}$ & 1.000 & - \\
\hline \multicolumn{3}{|l|}{ Marital status } \\
\hline Married & $0.591^{*}$ & $0.488,0.779$ \\
\hline Unmarried ${ }^{a}$ & 1.000 & - \\
\hline \multicolumn{3}{|l|}{ Employment } \\
\hline Employed & 1.134 & $0.832,1.544$ \\
\hline Unemployed $^{\mathrm{a}}$ & 1.000 & - \\
\hline \multicolumn{3}{|l|}{ Physical activity } \\
\hline Active & 1.058 & $0.806,1.389$ \\
\hline Inactive $^{a}$ & 1.000 & - \\
\hline \multicolumn{3}{|l|}{ Smoking } \\
\hline Smoker & 1.185 & $0.779,1.803$ \\
\hline Non-smoker ${ }^{a}$ & 1.000 & - \\
\hline \multicolumn{3}{|l|}{ Self-rated health } \\
\hline Good & $0.092^{*}$ & $0.058,0.148$ \\
\hline Fair & $0.328 *$ & $0.203,0.530$ \\
\hline Poor $^{a}$ & 1.000 & - \\
\hline LR statistics & \multicolumn{2}{|c|}{$210.440 *$} \\
\hline Correct explanation & \multicolumn{2}{|c|}{$97.60 \%$} \\
\hline Observations & \multicolumn{2}{|c|}{10141} \\
\hline
\end{tabular}

Note: ${ }^{*} p<0.05$. \#income divided by 100 . ${ }^{\text {a }}$ reference group. AOR refers to the adjusted odds ratio. $\mathrm{Cl}$ refers to the confidence interval.

Source: NHMS 2011

depression than females (AOR: 0.561). Compared with Indian/others, Malay (AOR: 0.615) and Chinese (AOR: 0.355 ) displayed lower odds of having depression.
Education level was significantly associated with a decreased probability of developing depression. In particular, individuals with tertiary-level (AOR: 0.627) and secondary-level education (AOR: 0.659) were less likely to develop depression compared with their peers with primary-level education. Married individuals had decreased odds of suffering from depression (AOR: 0.591). Individuals who self-rated their health as good (AOR: 0.092) and fair (AOR: 0.328) were less likely to have depression compared with individuals who self-rated their health as poor.

Table 3 presented the factors associated with the odds of having depression across ethnic groups. In terms of goodness-of-fit, the LR statistics of all the models were highly significant, and the proportions of correct explanation were also very high (95.90\%-98.80\%), and the constant terms were insignificant. These indicated that all the models were well developed. Income was only significantly associated with depression among Chinese. Specifically, an additional RM 100 of income raised the odds of having depression by $0.9 \%$. Malay males were less likely to have depression than Malay females (AOR: 0.305). However, there were no significant gender differences in depression among the Chinese and the Indians/others.

Among the Indians/others, individuals with secondary-level education displayed a lower likelihood of having depression compared with their peers with primary-level education (AOR: 0.587). The married Malays possessed lower odds of having depression than the unmarried Malays (AOR: 0.500). Smoking was only significant in explaining the odds of depression among the Malays, as the Malay smokers had twice the odds of suffering from depression compared with the Malay non-smokers (AOR: 2.083). Considering the association between self-rated health and depression, the Malays (AOR: 0.070), the Chinese (AOR: 0.028) and the Indians/others (AOR: 0.183) with self-rated good health were less likely to have depression than their counterparts with self-rated poor health. Similarly, the Malays (AOR: 0.246) and the Chinese (AOR: 0.161) who perceived their health as fair were less likely to report depression than their peers who perceived their health as poor.

\section{Discussion}

This study focused on the factors correlated with depression among adults in Malaysia. Analyses were stratified by ethnic groups. Using a sample of the Malaysian population and multivariable logistic regressions, age, gender, ethnicity, education, marital status and self-rated health were associated with the probability of developing depression. The younger adult, a lower education level, self-rated poor health, being female, unmarried, Malay and Chinese, Indian and others, were likely to suffer from depression. Considering the ethnic comparison, the relationships between depression and income, and smoking were only seen in the sample of the Chinese and the Malays. 
Table 3: Factors associated with depression, by ethnic groups

\begin{tabular}{|c|c|c|c|c|c|c|}
\hline \multirow{2}{*}{ Variables } & \multicolumn{2}{|c|}{ Malay } & \multicolumn{2}{|c|}{ Chinese } & \multicolumn{2}{|c|}{ Indian/others } \\
\hline & AOR & $95 \% \mathrm{Cl}$ & AOR & $95 \% \mathrm{Cl}$ & AOR & $95 \% \mathrm{Cl}$ \\
\hline Constant & 0.657 & $0.186,2.327$ & 0.880 & $0.083,9.355$ & 0.416 & $0.114,1.522$ \\
\hline Income $/ 100^{\#}$ & 0.982 & $0.962,1.002$ & $1.009 *$ & $1.003,1.016$ & 0.999 & $0.984,1.015$ \\
\hline Age & 0.990 & $0.974,1.007$ & 0.985 & $0.957,1.014$ & 0.986 & $0.970,1.002$ \\
\hline Family size & 0.989 & $0.907,1.077$ & 0.915 & $0.755,1.109$ & 0.996 & $0.919,1.081$ \\
\hline \multicolumn{7}{|l|}{ Gender } \\
\hline Male & $0.305^{*}$ & $0.165,0.562$ & 0.630 & $0.273,1.456$ & 0.902 & $0.534,1.525$ \\
\hline Female $^{a}$ & 1.000 & - & 1.000 & - & 1.000 & - \\
\hline \multicolumn{7}{|l|}{ Education } \\
\hline Tertiary & 0.849 & $0.409,1.765$ & 0.993 & $0.299,3.297$ & 0.635 & $0.316,1.275$ \\
\hline Secondary & 0.850 & $0.460,1.573$ & 0.971 & $0.347,2.720$ & $0.587^{*}$ & $0.361,0.955$ \\
\hline Primary $^{a}$ & 1.000 & - & 1.000 & - & 1.000 & - \\
\hline \multicolumn{7}{|l|}{ Marital status } \\
\hline Married & $0.500 *$ & $0.331,0.755$ & 0.756 & $0.345,1.653$ & 0.751 & $0.481,1.173$ \\
\hline Unmarried $^{\mathrm{a}}$ & 1.000 & - & 1.000 & - & 1.000 & - \\
\hline \multicolumn{7}{|l|}{ Employment } \\
\hline Employed & 1.486 & $0.920,2.398$ & 0.791 & $0.321,1.945$ & 1.129 & $0.686,1.859$ \\
\hline Unemployed ${ }^{\mathrm{a}}$ & 1.000 & - & 1.000 & - & 1.000 & - \\
\hline \multicolumn{7}{|l|}{ Physical activity } \\
\hline Active & 1.070 & $0.729,1.570$ & 0.785 & $0.370,1.666$ & 1.159 & $0.725,1.851$ \\
\hline Inactive $^{a}$ & 1.000 & - & 1.000 & - & 1.000 & - \\
\hline \multicolumn{7}{|l|}{ Smoking } \\
\hline Smoker & $2.083^{*}$ & $1.064,4.079$ & 1.001 & $0.288,3.476$ & 0.775 & $0.400,1.501$ \\
\hline Non-smoker ${ }^{a}$ & 1.000 & - & 1.000 & - & 1.000 & - \\
\hline \multicolumn{7}{|l|}{ Self-rated health } \\
\hline Good & $0.070^{*}$ & $0.034,0.143$ & $0.028^{*}$ & $0.010,0.080$ & $0.183^{*}$ & $0.080,0.415$ \\
\hline Fair & $0.246^{*}$ & $0.110,0.510$ & $0.161^{*}$ & $0.058,0.451$ & 0.563 & $0.244,1.299$ \\
\hline Poor $^{a}$ & 1.000 & - & 1.000 & - & 1.000 & - \\
\hline LR statistics & \multicolumn{2}{|c|}{$108.51^{*}$} & \multicolumn{2}{|c|}{$50.22^{*}$} & \multicolumn{2}{|c|}{$39.95^{*}$} \\
\hline Correct explanation & \multicolumn{2}{|c|}{$97.80 \%$} & \multicolumn{2}{|c|}{$98.80 \%$} & \multicolumn{2}{|c|}{$95.90 \%$} \\
\hline Observations & \multicolumn{2}{|c|}{5251} & \multicolumn{2}{|c|}{2579} & \multicolumn{2}{|c|}{2311} \\
\hline
\end{tabular}

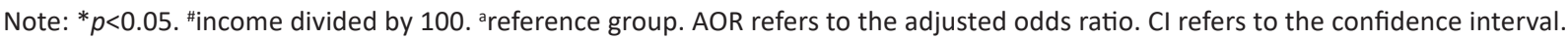
Source: NHMS 2011

The associations between income and income-related factors and depression had consistently been seen in past studies (14-16). Krishnaswamy et al. (14) examined the determinants of mental health disorders and found that having financial difficulty increased the likelihood of having depression. Similar findings were shown by Maideen et al. (15), who found that financial constraint raised the level of depression. Ganasegeran et al. (16) observed that lower income diabetic patients had more serious depression compared with their higher income counterparts because the former had poorer access to healthcare. In contrast, we found that the higher income Chinese were more likely to develop depression compared to their lower-income peers. Perhaps, the individuals with a higher income held a higher work position and consequently faced more stress. A statistical reason explaining why our results differed from the other Malaysian studies was the formatting of the income in our study as a continuous variable instead of a categorical variable, resulting in an inaccurate estimation of the AOR. Although statistically significant, the AOR was 
not necessarily clinically significant. For a better association of income and depression, the correlation between income and the work position should be estimated. The impact of income estimated in the present study was not large, but it was highly significant and should be noted by the policymakers with attention to the Chinese with a high income.

Several studies had analysed the relationship between age and depression $(8,16-17)$. Din and Noor (8) found more serious depression among younger women in the rural and urban areas compared to older women. Ganasegeran et al. (16) showed that older diabetic patients had a higher tendency to develop depression than younger diabetic patients with the fear of death and anxiety over diabetes induced diseases, in the former. Manaf et al. (17) reported that family liability increased with the ageing process, and with more stress in older people. However, the present study was consistent with Din and Noor (8) and found that older individuals were less likely to have depression compared with their younger counterparts, who had more household responsibilities and thus faced more stress. Although age as a continuous variable had its inherent inaccuracy in the estimation of its significance, policymakers should make a concerted effort to reduce depression among young adults, instead of the older adults, without a need to focus on any specific ethnic group as age was not significant in the sample of Malay, Chinese and Indian and the others.

The relationship between gender and depression was ambiguous. Krishnaswamy et al. (14) used the Clinical Interview Schedule-Revised to measure mental health disorder and found that women, as primary family caretakers, had higher odds of suffering from depression than men (24). Using a survey sample of adult patients, Manaf et al. (17) argued that men with a higher level of stress associated with their work and their role in providing the family members with financial support, were more likely to have depression than women. However, Aris et al. (25), in patients in primary care, found that gender was not associated with depression. Our findings supported Krishnaswamy et al. (14), that being female was positively associated with depression. The national policy targeted towards reducing the stress level among females, especially those from the Malay ethnic group might reduce the prevalence of depression.

The ethnic differences in depression had been investigated at the state-level in Malaysia amongst the elderly and the Indians with their poorer socioeconomic status were more likely to have severe depression than non-Indians (26). The association between ethnicity and depression had also been seen in the sample of diabetic patients and general population by Ganasegeran et al. (16), where the Indians faced the problems of ethnic discrimination and thus were more likely to develop depression. This study was somewhat consistent with these studies $(16,26)$. Given these findings, the government should concentrate more on the Indian than the Malay and the Chinese.
The education level was found to be negatively related to the likelihood of developing depression, which was consistent with the findings of past studies $(13,16,27)$. Mohd Sidik et al. (13) found that the less-educated elderly patients in a health clinic had a higher tendency to develop depression compared with the well-educated elderly. $\mathrm{Ng}$ and Tan (27) found that rural individuals with primarylevel education displayed higher odds of suffering from depression than their peers with secondary-level education and above. Similarly, Ganasegeran et al. found that the well-educated individuals had a better understanding of the causes of depression as well as the preventive measures (16). Nationwide intervention measures aimed at improving knowledge of mental health among individuals with poor education background would be worthy of consideration with particular attention to the Indians and the others with primary -level education.

The findings related to marital status were noteworthy. Previous studies found that being unmarried led to depression $(13-14,17)$ from the lack of spousal support (17). Thoits (28) emphasised that unmarried individuals faced more stress than married individuals because they seldom received social support. The present study found that married individuals, especially those from the Malay ethnic group were less likely to suffer from depression compared with their unmarried counterparts showing that marriage could play an important role in reducing depression. A national policy on depression could focus on unmarried segments of the population. Although encouraging marriage would seem effective in reducing depression, there was the possibility of unplanned marriage and early marriage with various social problems. Perhaps providing social support to those who are unmarried might prove a better alternative.

Studies related to smoking were inconclusive. Aris et al. found that smoking was not associated with depression (25). Verma et al. showed an insignificant relationship between smoking and depression (29). Ng and Tan found that smokers had a higher tendency to develop depression compared to non-smokers (27). In the present study, the Malay smokers were found to be twice more likely to develop depression compared with non-smokers. It was possible that individuals who were under stress would smoke and lead to a positive relationship between smoking and depression (30). Future studies should examine the reverse relationship between smoking and depression. Considering the outcomes, it would be important for policymakers to pay particular attention to smokers, especially Malay smokers.

The association between drinking and depression should be examined in future studies. Because of the prohibition of alcohol drinking in Islam, no Muslim would report alcohol consumption particularly to a Muslim interviewer (31). Since the majority of the respondents in the present study were Malay and therefore Muslim, the estimated results of expenditure on alcohol would be biased. To avoid biased results, alcohol drinking was not included as an explanatory variable. 
Self-rated good health was associated with reduced odds of having depression across all the ethnic groups, supporting past studies $(8,17)$. In particular, Manaf et al. found that individuals who perceived their health as very good were less likely to have anxiety than those who perceived their health as fair (17). Din and Noor found that depressive scores were positively associated with self-reported poor health (8). Diabetes and hypertension were also found related to depression (16). Individuals with poor health perhaps worried about their health and became depressed. Policies directed towards lowering the number of people suffering from depression should concentrate on individuals with poor health from all the ethnic groups.

Family size was statistically insignificant. The family size was a continuous variable, with the same statistical issue as income and age variables, and the association between family size and depression could be rejected easily. Several limitations were noteworthy. Our analysis was based on cross-sectional data, where the causal relationship between sociodemographic factors and depression were not well-identified, with the possibility that there were minor errors from the self-reported data. Other mental health illnesses, like generalised anxiety disorders (GAD) and suicidal behaviour, were not examined. Despite these limitations, some light had been shed on the factors associated with depression. In the future, a panel study on the changes in the factors associated with depression would be helpful and illuminating. Additionally, the relationship between depression and well-being, and health should be analysed, with income, age and family size as categorical variables for more accurate association between these variables and depression.

\section{Conclusion}

Ethnicity and age, gender, education, marital status and self-rated health were significantly associated with depression. Among the Chinese, higher income adults were more likely to acquire depression than lowerincome adults. Malay females were more likely to suffer from depression than Malay males. The less-educated Indians and others had a higher likelihood of falling into depression than the well-educated Indians and the others. Among the Malays, smokers were more likely to develop depression than non-smokers. However, self-rated poor health and being unmarried were positively associated with depression in the general population. A nationwide policy targeted towards reducing depression in these vulnerable people would be worthy of consideration.

\section{Acknowledgements}

The authors would like to thank the Director General of Health, Malaysia for his permission to use the data from the National Health and Morbidity Survey 2011 and to publish this paper. This research received funding from the Fundamental Research Grant Scheme (FRGS) (KOD SO 14218), which is sponsored by the Ministry of Education Malaysia.

\section{Competing interests}

The authors have no competing interests to declare.

\section{Financial Support}

This research received funding from the Fundamental Research Grant Scheme (FRGS) (KOD SO 14218), which is sponsored by the Ministry of Education Malaysia.

\section{Informed Consent}

Information sheet and consent form were made available for every respondent. For minor or disabled, signed consent was taken from the guardian with a witness. For illiterate respondent, thumbprint was also taken from the respondent with a literate person as the witness.

\section{Ethics Number}

NMRR-10-757-6837

\section{References}

1. World Health Organization. Depression: Fact sheet. 2017. Available from: http://www.who.int/ mediacentre/factsheets/fs369/en/

2. Keitner GI, Miller IW. Family functioning and major depression: An overview. Am J Psychiatry. 1990;147(9):1128-37.

3. Beck A, Crain AL, Solberg LI, Unutzer J, Glasgow $\mathrm{RE}$, Maciosek MV, et al. Severity of depression and magnitude of productivity loss. Ann Fam Med 2011;9(4):305-11.

4. Frank E, Dingle AD. Self-reported depression and suicide attempts among U.S. women physicians. Am J Psychiatry. 1999;156:1887-94.

5. Cheah YK, Azahadi M, Phang SN, Abd Manaf NH. Sociodemographic, lifestyle and health determinants of suicidal behaviour in Malaysia. Psychiatry Res. 2018;261:319-24.

6. Marcus M, Yasamy MT, van Ommeren M, Chisholm D, Saxena S. Depression: A global public health concern. 2012. Available from: http://www.who. int/mental_health/management/depression/who_ paper_depression_wfmh_2012.pdf

7. Saxena S, Thornicraft G, Knapp M, Whiteford H. Resources for mental health: Scarcity, inequity and inefficiency. Lancet. 2007;370(9590):878-89.

8. Din MO, Noor NM. Prevalence and factors associated with depressive symptoms in Malay women. Women Health. 2009;49(8):573-91.

9. The Star. More Malaysians expected to suffer from mental illness by 2020. 2016. Available from: http:// www.thestar.com.my/news/nation/2016/07/01/ more-malaysians-expected-to-suffer-from-mentalillness-by-2020/

10. Mukhtar F, Oei TPS. A review on the prevalence of depression in Malaysia. Curr Psychiatry Rev. 2011; 7(3):234-8. 
11. ZamZam R, Thambu M, Midin M, Omar K, Kaur P. Psychiatric morbidity among adult patients in a semiurban primary care setting in Malaysia. Int J Ment Health Syst. 2009;3:13.

12. Ng KT, Tan KL, Yadav H. Depression among the urban poor in Peninsular Malaysia: A community based cross-sectional study. J Health Psychol. 2013;18(1):121-7.

13. Mohd Sidik S, Mohd Zulkefli NA, Shah SA. Factors associated with depression among elderly patients in a primary health care clinic in Malaysia. Asia Pac Fam Med. 2003;2(3):148-52.

14. Krishnaswamy $S$, Subramaniam $K$, Jemain AA, Low WY, Ramachandran $\mathrm{P}$, Indran $\mathrm{T}$, et al. Common mental disorders in Malaysia: Malaysian mental health survey, 2003-2005. Asia Pac Psychiatry. 2012;4(3):201-9.

15. Maideen SFK, Sidik SM, Rampal L, Mukhtar F. Prevalence, associated factors and predictors of depression among adults in the community of Selangor, Malaysia. PLoS One. 9(4):e95395.

16. Ganasegeran K, Renganathan P, Manaf RA, Al-Dubai SAR. Factors associated with anxiety and depression among type 2 diabetes outpatients in Malaysia: A descriptive cross-sectional single-centre study. BMJ Open. 2014;4:e004794.

17. Manaf MRA, Qureshi AM, Lotfizadeh M, Ganasegeran K, Yadav H, Al-Dubai SA. Factors associated with anxiety and depression among outpatients in Malaysia: A cross-sectional study. MJPHM. 2016; 16(3):181-7.

18. Jia YF, Loo YT. Prevalence and determinants of perceived stress among undergraduate students in a Malaysian university. JUMMEC. 2018;21(1):1-5.

19. Institute for Public Health. National Health and Morbidity Survey 2011. Putrajaya: Ministry of Health Malaysia; 2011.

20. Sanchez-Villegas A, Schlatter J, Ortuno F, Lahortiga F, Pla J, Benito S, et al. Validity of a self-reported diagnosis of depression among participants in a cohort study using the structured clinical interview for DSM-IV (SCID-I). BMC Psychiatry. 2008;8:43.

21. Ainsworth $B E$, Haskell WL, Whitt MC, Irwin ML, Swartz AM, Strath SJ, et al. Compendium of physical activities: An update of activity codes and MET intensities. Med Sci Sports Exerc. 2000;32: (Suppl) S498-S516.

22. Cheah YK, Goh KL. Blood glucose screening among elderly Malaysians: Who to target? J Diabetes. 2017;9:85-92.

23. Cheah YK, Rasiah R. Analysis of the determinants of alcohol consumption among adult males in Malaysia. J Health Manag. 2017;19(1):28-38.

24. Gove WR. Gender differences in mental and physical illness: The effects of fixed roles and nurturant roles. Soc Sci Med. 1984;19(2):77-91.

25. Aris MAM, Halim NA, Musa R. Prevalence of depression and its associated risk factors in the primary care setting in Kuantan. J Adv Med Med Res. 2014;4(24):4201-9.

26. Rashid A, Tahir I. The prevalence and predictors of severe depression among the elderly in Malaysia. J Cross Cult Gerontol. 2015;30(1):69-85.

27. Ng KT, Tan KL. Prevalence and factors associated with depression among rural communities in Negeri Sembilan, Peninsular Malaysia. JSRR. 2014;3(12):1689-1702.

28. Thoits PA. Life stress, social support, and psychological vulnerability: Epidemiological considerations. J Community Psychol. 1982;10(4):341-62.

29. Verma RK, Min TH, Chakravarthy S, Barua A, Kar N. Sociodemographic correlates of unipolar major depression among the Chinese elderly in Klang Valley, Malaysia: An epidemiological study. Sci World J. 2014,2014:812712.

30. Cheah YK. The determinants of being a cigarette smoker: An exploratory study in Penang, Malaysia. IJBS. 2012;13(3):245-54.

31. Cheah YK. Socioeconomic determinants of alcohol consumption among non-Malays in Malaysia. Hitotsub J Econ. 2015;56:55-72. 